\title{
Increased glucose metabolism and ATP level in brain tissue of Huntington's disease transgenic mice
}

\author{
Judit Oláh ${ }^{1}$, Péter Klivényi ${ }^{2}$, Gabriella Gardián ${ }^{2}$, László Vécsei ${ }^{2}$, Ferenc Orosz ${ }^{1}$, Gabor G. Kovacs ${ }^{3}$, \\ Hans V. Westerhoff ${ }^{4,5}$ and Judit Ovádi ${ }^{1}$ \\ 1 Institute of Enzymology, Biological Research Center, Hungarian Academy of Sciences, Budapest, Hungary \\ 2 Department of Neurology, University of Szeged, Hungary \\ 3 Institute of Neurology, Medical University Vienna, Wien, Austria \\ 4 Department of Molecular Cell Physiology, Netherlands Institute for Systems Biology, Free University, Amsterdam, Netherlands \\ 5 Manchester Centre for Integrative Systems Biology, UK
}

\author{
Keywords \\ biosimulation; channelling; energy \\ metabolism; glycolysis activation; \\ Huntington's disease

\section{Correspondence \\ J. Ovádi, Institute of Enzymology, Biological \\ Research Center, Hungarian Academy of \\ Sciences, Karolina út 29, H-1113 Budapest, \\ Hungary \\ Fax: +3614665465 \\ Tel: +36 12793129 \\ E-mail: ovadi@enzim.hu} \\ Website: http://www.enzim.hu/ ovadi
}

\section{Note \\ The mathematical models described here have been submitted to the Online Cellular Systems Modelling Database and can be accessed free of charge at http://jij. biochem. sun.ac.za/database/olah2cc/index.html; http://jj].biochem.sun.ac.za/database/ olah2cb/index.html; http://jjj. biochem.sun.ac. za/database/olah2hdc/index.html; http:// jjj.biochem.sun.ac.za/database/olah2hdb/ index.html}

(Received 17 June 2008, revised 17 July 2008, accepted 23 July 2008)

doi:10.1111/j.1742-4658.2008.06612.x
Huntington's disease (HD) is a progressive neurodegenerative disorder characterized by multifarious dysfunctional alterations including mitochondrial impairment. In the present study, the formation of inclusions caused by the mutation of huntingtin protein and its relationship with changes in energy metabolism and with pathological alterations were investigated both in transgenic and 3-nitropropionic acid-treated mouse models for HD. The HD and normal mice were characterized clinically; the affected brain regions were identified by immunohistochemistry and used for biochemical analysis of the ATP-producing systems in the cytosolic and the mitochondrial compartments. In both HD models, the activities of some glycolytic enzymes were somewhat higher. By contrast, the activity of glyceraldehyde3-phosphate dehydrogenase was much lower in the affected region of the brain compared to that of the control. Paradoxically, at the system level, glucose conversion into lactate was enhanced in cytosolic extracts from the HD brain tissue, and the level of ATP was higher in the tissue itself. The paradox could be resolved by taking all the observed changes in glycolytic enzymes into account, ensuing an experiment-based detailed mathematical model of the glycolytic pathway. The mathematical modelling using the experimentally determined kinetic parameters of the individual enzymes and the well-established rate equations predicted the measured flux and concentrations in the case of the control. The same mathematical model with the experimentally determined altered $V_{\max }$ values of the enzymes did account for an increase of glycolytic flux in the HD sample, although the extent of the increase was not predicted quantitatively. This suggested a somewhat altered regulation of this major metabolic pathway in HD tissue. We then used the mathematical model to develop a hypothesis for a new regulatory interaction that might account for the observed changes; in HD, glyceraldehyde-3-phosphate dehydrogenase may be in closer proximity (perhaps because of the binding of glyceraldehyde-3-phosphate dehydrogenase to huntingtin) with aldolase and engage in channelling for

\footnotetext{
Abbreviations

3-NP, 3-nitropropionic acid; CK, creatine kinase; DHAP, dihydroxyacetone phosphate; GAP, glyceraldehyde-3-phosphate; GAPDH, glyceraldehyde-3-phosphate dehydrogenase; GDH, glycerol-3-phosphate dehydrogenase; GFAP, glial fibrillar acidic protein; GLUDH, glutamate dehydrogenase; HD, Huntington's disease; HK, hexokinase; LDH, lactate dehydrogenase; PK, pyruvate kinase.
} 
glyceraldehyde-3-phosphate. By contrast to most of the speculation in the literature, our results suggest that the neuronal damage in HD tissue may be associated with increased energy metabolism at the tissue level leading to modified levels of various intermediary metabolites with pathological consequences.

Huntington's disease (HD) is a progressive neurodegenerative disorder, which is inherited in an autosomal dominant fashion [1]. It affects approximately one in 10000 individuals. The disease is characterized by motor and cognitive symptoms as well as personality changes [2]. In HD, the neurodegeneration predominantly afflicts the medium spiny neurones in the striatum, although loss of neurones in the deep layers of the cerebral cortex has also been reported [3].

At the genetic level, HD is caused by the expansion of the CAG repeat from 36 times up to 180 times. This repeat codes for long stretches of polyglutamine in the $\mathrm{N}$-terminal region of huntingtin protein [4]. Various disease mechanisms have been suggested, including transcriptional dysregulation, protein misfolding and degradation, oxidative stress, excitotoxic processes, impairment in intracellular transport or mitochondrial function, and perturbation of synaptic transmission $[5,6]$. However, the relationship between the expression of mutant huntingtin protein and the dysfunction of mitochondria that manifests itself in the energy impairment suggested for HD [7] is not understood in detail. Data from post mortem tissues (caudate and putamen of the striatum) of HD patients [8,9] suggest decreased activities of mitochondrial respiratory chain complexes. However, the data referring to in vivo ATP, lactate, creatine and phosphocreatine levels, as measured by NMR in HD patients, are conflicting [10-12]. In a recent study, striatal glucose metabolism has been reported to be normal or reduced in presymptomatic HD individuals, whereas striatal hypometabolism has been observed consistently in symptomatic HD patients. Thalamic and cerebellar hypermetabolism as well as cortical hypometabolism and hypoperfusion have also been seen in early stage and symptomatic HD patients with positron emission tomography or single-photon emission computed tomography [13]. In vitro binding of glyceraldehyde-3-phosphate dehydrogenase (GAPDH; EC 1.2.1.12), a glycolytic enzyme, to the polyglutamine tail of the mutant protein has been reported [14]. However, the functional consequences of this interaction are unclear. Various scenarios have been proposed concerning the effect of the CAG expansion on the GAPDH-related events, including changes in the enzyme level or enzymatic activity leading to cell death [15]. The activity of GAP-
DH was measured in HD post mortem brain $[8,15]$ and, even if it decreased in some specific brain regions, the decrease was small [15]. Significantly decreased GAPDH activity was detected in fibroblasts from HD patients, specifically after the cells had been insulted in various ways $[16,17]$. In HD transgenic mice, overexpression and nuclear translocation of the enzyme was demonstrated in discrete populations of brain neurones [18]. It has been suggested that the nuclear translocation and associated cytotoxicity of mutant huntingtin is mediated by GAPDH and the ubiquitin-E3-ligase Siah1 [19]. Because of the indications that GAPDH may be involved in the pathology of HD, in the present study we examined its role in HD tissue with an emphasis on its metabolic roles.

The development of three different HD (neurotoxintreated, knock-in and transgenic) mouse models has been a milestone in the research of the disease [20]. The mice administered with neurotoxin 3-nitropropionic acid (3-NP) display characteristics of HD, including clinical symptoms and striatal pathology [21,22]. The first successful mouse model of HD was that of the R6 mouse, which was generated by introducing and overexpressing exon 1 of the human gene encoding huntingtin with long CAG repeat expansions [23]. Low weight, diabetes, clasping, tremor and convulsions are characteristics of the R6/2 line. The behavioural anomalies are followed by an early death at 10-13 weeks. Pathological examination of the brain revealed inclusions in the nucleus of most brain neurones as early as 7 weeks of age, which were preceded by an abnormal location of huntingtin (i.e. in the nucleus) [20]. A commonly used transgenic animal model is the N171-82Q mouse, which expresses the first 171 amino acids of human huntingtin with 82 polyglutamine repeats exclusively in brain, with the level of the transgene product remaining lower than the level of the endogenous full-length huntingtin [24]. These animals suffered a shortened lifespan, progressive behavioural symptoms and other characteristics resembling the pathology of HD patients. The phenotype begins at approximately 90 days of age and, on average, death occurs approximately 45 days later [24,25]. These mouse models offer the possibility to test the idea that HD is indeed associated causally with altered activity or concentration of GAPDH. 
Mitochondrial dysfunction and the associated impairment of energy metabolism are among the main reasons thought to underlie the pathogenesis of HD. It has been proposed to be directly connected with the impairment of energy metabolism in HD $[5,6]$. Reduced ATP production was suggested to be due to the inhibition of the activities of mitochondrial complexes of electron transport; the inhibition of the activity of complex II was indeed observed in brain of mouse treated with 3-NP [22].

In the present study, a kinetic analysis of both glycolysis and the mitochondrial respiratory chain is presented comparing affected with non-affected regions of the brain of N171-82Q transgenic and 3-NP treated mice. The results obtained from an integrated experimentation and modelling reveal and suggest relations between the changes in morphology, glycolytic flux, ATP production and ATP levels.

The mathematical models described here have been submitted to the Online Cellular Systems Modelling Database and can be accessed free of charge at http://jjj.biochem.sun.ac.za/database/olah2cc/index. html; http://jjj.biochem.sun.ac.za/database/olah2cb/index. html; http://jjj.biochem.sun.ac.za/database/olah2hdc/ index.html; http://jij.biochem.sun.ac.za/database/olah2hdb/ index.html.

\section{Results}

\section{Characterization of the HD mouse model: clinical symptoms, protein expression and identification of the affected brain areas}

In our experiments, N171-82Q transgenic and normal control mice [24] were used. The transgenic mice developed a progressive neurological disorder starting at 12-16 weeks of age, and exhibited an uncoordinated gait, hypoactivity, stereotypic movements and shakinglike tremor. In the end-stage (20-24 weeks of age), the mice lost weight and appeared to be less responsive to stimuli and severely hypokinetic. Chronic, systemic administration of 3-NP to normal mice resulted in an initial motor hypoactivity followed by occasional periods of hyperactivity with abnormal movements, including irregular tremor, head bobbing, head tilting and circling.

The levels of the endogenous (wild-type) huntingtin protein and the transgene product were examined by western blotting using anti-huntingtin serum raised against the first 17 amino acids of the $\mathrm{N}$-terminal part of the protein. We found that the N171-82Q mutant protein was expressed in the brain homogenates. However, its level was significantly lower than that of the mouse wild-type (data not shown) in accordance with the data available in the literature [24].

The affected and the unaffected brain tissues as well as the whole brain of the HD and of control mice were used for our studies. The affected brain regions were identified by immunohistochemistry using anti-ubiquitin and anti-huntingtin sera (Fig. 1). In the control mice, neither huntingtin nor ubiquitin immunoreactive nuclear inclusions were detected. Nuclear inclusions were found in the granular layer of the cerebellum of the transgenic mice (Table 1 and Fig. 1A,B) in agreement with the literature [24]. Significant numbers of inclusions were detected in the hippocampus (Table 1). Some of these nuclear inclusions were huntingtin and ubiquitin immunopositive in four out of five animals


Fig. 1. Immunohistochemistry for (A) huntingtin, (B) ubiquitin and (C-F) GFAP in the transgenic mice examined. Representative photographs of the $(A, B, F)$ granular layer of the cerebellum, $(C)$ hippocampus, (D) frontal cortex and (E) striatum. Magnification: $\times 400$ (A, B), $\times 100(C-F)$. Arrows indicate representative dark brown anti-huntingtin and anti-ubiquitin immunoreactive nuclear inclusions visible in blue nuclei stained with hematoxylin nuclear stain. Anti-GFAP immunopositive, reactive astrocytes, which should be stained brown, were not demonstrated in the frontal cortex, nor the basal ganglia and the cerebellar cortex. (D-F) Note the usual GFAP immunopositivity of nonreactive fibrillary astrocytes in the white matter. WM, white matter; CC, corpus callosum; Mol, molecular layer; Gran, granular layer of the cerebellum. 
Table 1. Semiquantitative scoring of reactive astrogliosis as detected by GFAP immunostaining and of the number of nuclear inclusions detected by ubiquitin and huntingtin immunostaining. -, none; +, mild/occasional; ++, moderate; +++, severe/many. HD-3, Huntington diseased animal, number 3 from the transgenic strain.

\begin{tabular}{|c|c|c|c|c|c|c|}
\hline Region/alteration & HD-1 & HD-2 & HD-3 & HD-4 & HD-5 & Control \\
\hline \multicolumn{7}{|l|}{ Reactive gliosis } \\
\hline Frontal cortex & - & + & - & + & + & - \\
\hline Hippocampus & +++ & ++ & +++ & +++ & +++ & - \\
\hline Striatum & - & - & - & - & - & - \\
\hline Thalamus & - & - & - & - & - & - \\
\hline Cerebellum & - & - & - & - & - & - \\
\hline Brainstem & - & - & - & + & + & - \\
\hline \multicolumn{7}{|l|}{ Nuclear inclusion } \\
\hline Frontal cortex & + & - & - & - & - & - \\
\hline Hippocampus & ++ & + & ++ & ++ & + & - \\
\hline Striatum & + & - & + & + & + & - \\
\hline Thalamus & - & - & - & - & - & - \\
\hline Cerebellum $^{a}$ & +++ & +++ & +++ & +++ & ++ & - \\
\hline Brainstem & - & - & - & - & - & - \\
\hline
\end{tabular}

${ }^{a}$ Granular layer of cerebellum.

in the striatum and in a single animal in the frontal cortex (Table 1). Prominent reactive astrogliosis, a characteristic feature of the early neuronal damage in HD [26], was demonstrated in the hippocampus by anti-glial fibrillar acidic protein (GFAP) immunostaining (Fig. 1C); this was mild in the frontal cortex (Fig. 1D). Virtually no such immunoreactivity was found in the striatum (Fig. 1E) and cerebellar cortex (Fig. 1F). On the basis of these data, the posterior portion, which includes the major part of the striatum, thalamus and hippocampus, was used to represent the HD-affected region. By contrast, neither inclusion formation nor early neuronal damage befell for the anterior portion of the brain, which includes the frontal cortex and minor part of the striatum, whereas the cerebellum contained large numbers of inclusions without evidence of neuronal damage.

The neurotoxin 3-NP-administered mice had some features characteristic for HD, including clinical symptoms and striatal pathology, as described previously [21].

\section{The glycolytic enzymes}

Glucose is the major Gibbs energy source of brain. It is metabolized primarily via glycolysis. To evaluate the effect of the expression of the mutant huntingtin protein on the molecular basis of glycolysis, we measured the activities of the glycolytic enzymes (Table 2). Cellfree extracts were prepared from the affected (posterior) and unaffected (anterior and cerebellum) regions of the HD, from the neurotoxin-administered as well as from the control mice. In some cases, extracts were prepared from the whole brain tissue as well.

The activities of three glycolytic enzymes [i.e. hexokinase (HK; EC. 2.7.1.1), enolase (EC 4.2.1.11) and pyruvate kinase (PK; EC. 2.7.1.40)] were slightly higher in the posterior region of the transgenic HD mice (Table 2), whereas no change was detected in the unaffected regions (data not shown). In the 3-NP mice, the activity of HK had increased more than in the transgenic mice (Table 2).

Table 2. $V_{\max }$ activities determined experimentally in posterior brain homogenates from the two mouse models of HD. Data are the means of three to five different sets of experiments (three to five different animals) and the means \pm SEM are shown. Differences were analysed using Student's t-test. ND, not determined. GPI, glucose-6-phosphate isomerase (EC 5.3.1.9); PFK, phosphofructokinase (EC 2.7.1.11); TPI, triosephosphate isomerase (EC. 5.3.1.1).

\begin{tabular}{|c|c|c|c|c|}
\hline \multirow[b]{3}{*}{$\begin{array}{l}\text { Enzyme } \\
\left(\mu \mathrm{mol} \cdot \mathrm{g}^{-1} \cdot \mathrm{min}^{-1}\right)\end{array}$} & \multicolumn{2}{|c|}{ Mice treated with 3-NP } & \multicolumn{2}{|c|}{ Transgenic mice expressing N171-820 } \\
\hline & Control & 3-NP & Control & N171-820 \\
\hline & \multicolumn{2}{|l|}{ CFLP strain } & \multicolumn{2}{|c|}{$\begin{array}{l}\text { N171-82O/ B6C3F1 strain, wild-type littermates } \\
\text { as control }\end{array}$} \\
\hline HK & $40 \pm 12$ & $70 \pm 6(P<0.01)$ & $11.4 \pm 1.5$ & $16.9 \pm 1.6(P<0.05)$ \\
\hline GPI & $3290 \pm 420$ & $3210 \pm 390$ & ND & ND \\
\hline PFK & $420 \pm 52$ & $566 \pm 61(P<0.10)$ & $247 \pm 50$ & $256 \pm 14$ \\
\hline Aldolase & $287 \pm 35$ & $234 \pm 49$ & $276 \pm 40$ & $238 \pm 25$ \\
\hline TPI & $13800 \pm 1400$ & $13200 \pm 1100$ & $11100 \pm 1090$ & $10990 \pm 1100$ \\
\hline GAPDH & $1180 \pm 190$ & $857 \pm 63(P<0.10)$ & $676 \pm 30$ & $388 \pm 17(P<0.005)$ \\
\hline Enolase & ND & ND & $682 \pm 23$ & $868 \pm 70(P<0.05)$ \\
\hline PK & $868 \pm 130$ & $639 \pm 64(P<0.10)$ & $358 \pm 41$ & $520 \pm 67(P<0.10)$ \\
\hline $\mathrm{LDH}$ & $3110 \pm 270$ & $3390 \pm 300$ & $2490 \pm 110$ & $2030 \pm 290$ \\
\hline $\mathrm{GDH}$ & ND & ND & $170 \pm 25$ & $165 \pm 19$ \\
\hline
\end{tabular}




\section{GAPDH}

GAPDH was of special interest because it has been reported to bind to the polyglutamine repeat of the mutant huntingtin protein [14]. Indeed, GAPDH activity in the cell-free extracts from the affected (posterior) region of both the transgenic mice and the neurotoxintreated animals was $30-50 \%$ lower than in the cell-free extracts from the same regions of the control animals (Table 2). Consistent with this, a smaller (15\%) decrease was detected in the GAPDH activities of the whole brain homogenates of the diseased animals (data not shown).

Because GAPDH activity was lower in the HD tissues, we expected the concentration of the substrate of this reaction to be increased in HD. In extracts of the posterior brain region of control and HD mice in the presence of excess ATP, $\mathrm{NAD}^{+}$, inorganic phosphate and glucose, we determined the total concentration of the triosephosphates [glyceraldehyde-3-phosphate
(GAP) and dihydroxyacetone phosphate (DHAP)]. Because of the small amount of posterior tissue of the HD animals (used also for the immunohistochemistry and for the optimization of the assay conditions), the concentrations could only be determined at two time points (35 and $120 \mathrm{~min}$ ). In line with our expectation, we found the total concentration to be increased in HD (i.e. from some $18 \mu \mathrm{M}$ to $24 \mu \mathrm{M}$ at $35 \mathrm{~min}$ and $31 \mu \mathrm{M}$ at 120 min after addition of glucose; Fig. 2B). For the second time point, the increase was highly significant $(P<0.01)$.

\section{Glycolysis at the system level: a surprise}

The decrease in GAPDH activity accompanied by an increase in triosephosphate concentrations suggested that the difference between healthy and HD tissue might well be understood in terms of the effect on GAPDH activity and the consequences thereof. Through sequestration of GAPDH, the increased


Fig. 2. Flux measurements (the conversion of glucose to lactate) and simulation in the posterior brain extracts of control and $\mathrm{N} 171-82 \mathrm{Q}$ transgenic mice. (A) The NADH absorbance in the control (solid line) and the transgenic N171-82O (dashed line) mice. (B) Triosephosphate formation, (C) pyruvate formation and (D) lactate production in the case of the control and the transgenic N171-82Q mice. (B-D) Measured (circle for control, triangle for transgenic N171-820 mice) and simulated (solid line for control, dashed line for transgenic N171-820 mice) curves are shown. The dotted lines show the results of the simulation for the transgenic N171-82O mice when only the measured activities of the glycolytic enzyme activities were taken into account (Table 2). The formation of metabolites (B-D) was followed by the two-step method when, after $\mathrm{HClO}_{4}$ precipitation and neutralization, the metabolites were determined by enzymatic assay. The protein concentration was (A) $0.14 \mathrm{mg} \cdot \mathrm{mL}^{-1}$ or (B-D) $0.28 \mathrm{mg} \cdot \mathrm{mL}^{-1}$ in the cuvette. At least three different sets of experiments were carried out; the SEM for the determination was $\pm 15 \%$ within each set of experiments. 
expression level of huntingtin would lead to inactivation or degradation of the enzyme. The inhibition of GAPDH would then also lead to a decreased glycolytic flux and a decreased level of ATP, compromising the affected cells energetically. We decided to test this scenario. The glycolytic flux and the level of ATP, however, are systemic properties (i.e. consequences of the simultaneous activity of many enzymes) and this required a different, more system biological perspective.

The addition of glucose to the cell-free cytosolic extract of normal and HD tissue should not only activate $\mathrm{HK}$, but also set the glycolytic pathway in motion, by filling the subsequent metabolite pools, ultimately leading to the production of lactate. After a transient period that is necessary to fill up the metabolite pools, a (quasi-)steady state should be attained, in which the metabolic intermediates become constant over time. Because the product lactate is not taken away from the medium in a cytosolic extract, its concentration should increase with time. To the extent that glycolytic reactions are sensitive to back pressure from lactate, as is the lactate dehydrogenase reaction, their substrate concentrations also should increase with time. The results for the control tissue (Fig. 2B-D, circles) are in line with the above expectations. There was a substantial production of lactate. The intermediate preceding lactate (i.e. pyruvate) increased in parallel, but to much lower levels, whereas the intermediates DHAP and GAP, higher up in the glycolytic chain, increased within $30 \mathrm{~min}$ to a steady and low level of approximately $18 \mu \mathrm{M}$. Under these conditions, the $\mathrm{NADH} / \mathrm{NAD}^{+}$ratio reflects the balance between the NADH oxidizing and the NAD ${ }^{+}$ reducing reactions. As shown by the solid line in Fig. 2A, during the first $60 \mathrm{~min}$, there appeared to be a net accumulation of NADH, in parallel to the accumulation of pyruvate. This is in line with expected slight deceleration of lactate dehydrogenase with increased lactate concentrations. Thereafter, NADH decreased somewhat with time.

The extract from the HD tissue exhibited qualitatively the same behaviour, with two exceptions. First, expecting that the decreased activity of GAPDH had led to a decreased glycolytic flux, we were surprised to find that the rates of production of lactate and pyruvate were approximately two-fold higher than in the non-HD extracts. The flux almost doubled from approximately $11 \mu \mathrm{mol} \cdot \mathrm{g}^{-1} \cdot \mathrm{min}^{-1}$ of lactate, but remained well below the $V_{\max }$ of the glycolytic enzymes, becoming closest to that of hexokinase, which increased from 11.4 to $16.9 \mu \mathrm{mol} \cdot \mathrm{g}^{-1} \cdot \mathrm{min}^{-1}$ (Table 2). Second, in HD, DHAP and GAP continued to increase with time, as did the NADH.

\section{Is the enhanced glycolytic flux consistent with the altered enzyme activities?}

The above experimental observation of an increased flux through the glycolytic pathway, and presumably also through the GAPDH step itself, appeared to be at odds with the decreased GAPDH activity also observed in the HD case. On the other hand, the activities of other glycolytic enzymes appeared to be increased in HD and, after all, the flux is a collective property of all the enzymes in the pathway. To examine this issue further, we needed a systems biology approach [27-29]. We developed an experiment-based mathematical model for the biosimulation of the glucose metabolism in the cytosol of mouse brain. The model included the kinetic parameters of the glycolytic enzymes in normal brain tissues as established by ourselves (Table 2) and others (Doc. S4). The rate equations of the individual enzyme reactions were also taken from previous publications by ourselves and others (Doc. S4). Together, the information used in the model corresponds to the best possible knowledge available in the current literature.

We first examined whether the fluxes and concentrations observed under normal conditions were in line with what should be expected from the measured activities of the individual enzymes. We computed the time course of the formation of triosephosphates, pyruvate and lactate in the control sample by using the $V_{\max }$ values of the glycolytic enzymes determined experimentally (Table 2 ) at excess glucose, $\mathrm{NAD}^{+}$ and ATP concentrations. Because we noticed that the $\mathrm{NADH}$ was consumed by a side reaction, such as the glycerol-3-phosphate dehydrogenase (GDH; EC. 1.1.1.8) catalysed reaction, we also determined the $V_{\max }$ value of this reaction in brain tissues (in this case, there was no difference regardless of whether control or HD samples were used) (Table 2). The reactions with these kinetic parameters were included in the basic model as well. As shown in Fig. 2B-D, all three progress curves computed with the same parameter set corresponded well to the values of the measured metabolite concentrations for the control case (full circles). Although the test with only six data points (which is all we conducted in view of sample limitations) is of limited strength, this finding suggests that the model is appropriate to describe the changes of the metabolite concentrations in time in cytosolic extract.

We next considered whether the changes in enzyme levels observed in HD could be responsible for the paradoxical increase in glycolytic flux and reduced activity of GAPDH. We computed the rate of the 
formation of the same three metabolites [i.e. triosephosphates (Fig. 2B), pyruvate (Fig. 2C) and lactate (Fig. 2D)] by using the $V_{\max }$ values of the glycolytic enzymes determined experimentally for the HD brain sample (Table 2). The computed fluxes (Fig. 2B-D, dotted lines) were significantly higher than that of the control, consistent with the data presented in Fig. 2A. This suggested that a decreased activity of GAPDH was consistent with an increase in flux. Because hexokinase had a much higher control coefficient with respect to the glycolytic flux (not shown), its increase more than compensated for the decrease in GAPDH activity. We conclude that the increased glycolytic flux in HD is consistent with the reduced GAPDH activity.

\section{Activity of mitochondrial complexes}

In the intact tissue, some of the pyruvate should be oxidized by pyruvate dehydrogenase complex in the mitochondria rather than by lactate dehydrogenase (LDH; EC. 1.1.1.27), with the carbon then entering the tricarboxylic acid cycle and the corresponding redox equivalents being oxidized by the mitochondrial respiratory chain. We therefore determined the activities of the mitochondrial complexes in homogenates of mitochondria isolated from the brains of control and HD mice. Due to the limited availability of posterior section material, whole brain tissues were used for these experiments. As shown in Table 3, there was no decrease in the activities of the mitochondrial complexes in the case of the transgenic HD mice. Complex I activity was increased significantly and the activities of other complexes

Table 3. Mitochondrial complex activities in the different mouse models of HD. Data are the means of three to five different sets of experiments (individual mice), and the means \pm SEM are shown. Differences were analysed using Student's t-test. In the case of 3-NP treated mice, two or three mice were investigated. ND, not determined

\begin{tabular}{|c|c|c|c|}
\hline $\begin{array}{l}\text { Whole brain } \\
\text { homogenate, } \\
\left(\mu \mathrm{mol} \cdot \mathrm{g}^{-1} \cdot \mathrm{min}^{-1}\right)\end{array}$ & Control & $\begin{array}{l}\text { Mice } \\
\text { treated } \\
\text { with 3-NP }\end{array}$ & $\begin{array}{l}\text { Transgenic mice } \\
\text { expressing } \\
\text { N171-82Q }\end{array}$ \\
\hline GLUDH & $24 \pm 4$ & $\begin{array}{l}38 \pm 3 \\
(P<0.05)\end{array}$ & $37 \pm 0.6(P<0.05)$ \\
\hline Complex I & $26 \pm 3$ & $26 \pm 3$ & $35 \pm 2(P<0.05)$ \\
\hline Complex II & $141 \pm 15$ & $\begin{array}{l}27 \pm 2 \\
(P<0.005)\end{array}$ & $157 \pm 27$ \\
\hline Complex I/III & $28 \pm 6$ & ND & $25 \pm 4$ \\
\hline Complex II/III & $195 \pm 13$ & ND & $191 \pm 10$ \\
\hline Complex IV & $1060 \pm 220$ & ND & $969 \pm 34$ \\
\hline
\end{tabular}

appeared unchanged. As expected, the activity of complex II was reduced (to $20 \%$ ) in mice treated with 3-NP. The activity of glutamate dehydrogenase (GLUDH; EC. 1.4.1.2), a mitochondrial marker enzyme, was increased by approximately $50 \%$ in both the 3-NP treated and the transgenic mice. We conclude that HD per se may not be accompanied by a reduced activity of the mitochondrial respiratory chain, but that an increase of GLUDH may be part of the pathology. Potentially, an increased mitochondrial compartment, defined in terms of GLUDH activity, compensates for decreased activities of complexes II-IV per mitochondrion.

\section{ATP level}

The increased glycolytic activity at constant activity of the mitochondrial respiratory chain would suggest an increased activity of ATP synthesis. To examine whether this increased activity was reflected by an increased level of ATP, we determined the ATP concentration in the homogenate of the posterior brain regions of control and transgenic N171-82Q mice by enzymatic assay. The ATP concentration in the control sample was almost $3 \mu \mathrm{mol} \cdot \mathrm{g}^{-1}$ of protein, which is similar to the concentration previously reported [30]. As shown in Table 4, the ATP concentration was two-fold higher in the HD sample. Significantly higher ATP concentrations were established in several experiments using either affected or whole brain extracts of the HD mice compared to normal mice. Due to the limited availability of HD brain sample, the ADP could not be measured.

As further indicators of energy metabolism, we looked at creatine and creatine kinase (CK; EC 2.7.3.2). We found that the CK activity was slightly increased in HD tissue. This was accompanied by a decrease in the creatine concentration in the transgene mice compared to the control (Table 4).

Table 4. Metabolite concentrations and $C K$ activity in the transgenic mouse model of HD. Data are the means of three to five measurements. Usually three to five different sets of experiments were carried out and the means \pm SEM are shown. Differences were analysed using Student's $t$-test.

\begin{tabular}{lcc}
\hline $\begin{array}{l}\text { Posterior brain } \\
\text { homogenate }\end{array}$ & Control & $\begin{array}{l}\text { Transgenic mice } \\
\text { expressing N171-82O }\end{array}$ \\
\hline CK $\left(\mu \mathrm{mol} \cdot \mathrm{g}^{-1} \cdot \mathrm{min}^{-1}\right)$ & $2040 \pm 220$ & $2308 \pm 190$ \\
Creatine $\left(\mu \mathrm{mol} \cdot \mathrm{g}^{-1}\right.$ protein) & $149 \pm 11$ & $116 \pm 20(P<0.10)$ \\
Lactate $\left(\mu \mathrm{mol} \cdot \mathrm{g}^{-1}\right.$ protein $)$ & $402 \pm 95$ & $336 \pm 81$ \\
ATP $\left(\mu \mathrm{mol} \cdot \mathrm{g}^{-1}\right.$ protein $)$ & $2.8 \pm 0.4$ & $6.4 \pm 1.4(P<0.05)$ \\
\hline
\end{tabular}




\section{Learning from an iteration between modelling and experimentation}

Although Fig. 2 shows that the increased in glycolytic flux was consistent with the decreased GAPDH activity, the correspondence between experimental and modelling results for the HD case was incomplete. In particular, the increase in HD of the pyruvate was smaller, and the increase in lactate flux was stronger than predicted on the basis of the changes in $V_{\max }$. We examined the possibility that not only the expression levels of the same isoenzymes was altered in HD, but also different isoenzymes had been brought to expression, or that our in vitro $V_{\max }$ changes were not quite representative of the flux changes in the cyosolic extract. As summarized in Table 5, a further increase in the $V_{\max }$ values of all glycolytic enzymes, or of only $\mathrm{HK}$, did not result in good fits for lactate and pyruvate. An increase of the $V_{\max }$ of GAPDH to that of the control sample without, or with, an increase of HK activity was also unsuccessful. Subsequently, we reduced the $K_{\mathrm{m}}$ values of GAP for GAPDH, which resulted in positive alterations. The optimal parameter set for the computation of the concentrations of the three glycolytic intermediates was obtained when the $K_{\mathrm{m}}$ values of GAP for the GAPDH and aldolase (EC 4.1.2.13) were decreased, and the $V_{\max }$ value of $\mathrm{HK}$ reaction was increased (model $6 \mathrm{~b}$ ) to the same extent as observed with the sample of neurotoxin-treated mice (Table 2). Tables 2 and 5 show the parameters used for successful simulation of the three metabolites (triosephosphates, pyruvate and lactate) measured with control and HD samples under test tube conditions.

\section{Prediction of the steady-state flux and intermediate concentrations in the posterior regions of intact brain in normal and HD mice}

The availability of an in silico representation of the glycolytic pathway in both normal and HD brain offers the potential for prediction of other properties that have not been or cannot be measured. First, we computed the conversion of glucose to pyruvate with the equations and parameter sets found to be optimal to describe the experimentally determined data for the normal and HD brain tissue extracts. We were confronted with the fact that the respective $V_{\max }$ had been measured in diluted extracts; to correct for the dilutions, the concentrations ( $V_{\max }$ values) of the individual enzymes as determined in the cytosolic extract were increased 100-fold, which corresponds to an in vivo concentration of approximately $30 \mathrm{~g} \cdot \mathrm{L}^{-1}$ of cytosolic protein. The concentrations and ratios of nucleotides, $\mathrm{NAD}^{+} / \mathrm{NADH} \quad(1 \mathrm{~mm} / 0.1 \mathrm{~mm})$ and ATP/ADP (2 mM/0.2 mM) were kept constant at levels corresponding to the intracellular ones [31]. The glucose concentration ( $2 \mathrm{~mm})$ was also kept constant corresponding to equilibrated influx of glucose. A constant efflux rate constant and first-order kinetics were assumed for pyruvate transport from the cytoplasm into the mitochondrium, which ensured a

Table 5. Searching for the optimal parameter set for computation of the changes of glycolytic metabolites measured experimentally. Rows refer to subsequent models in the optimization series. The 'basic' model was evaluated using the rate equations and the experimentally determined kinetic parameters of the individual enzymes (see Table 2 and Doc. S4). The criteria for the goodness of simulation is based upon the deviation of the simulated metabolite concentrations from the measured ones: good and very good indicate semi-quantitatively less than $15 \%$ and $5 \%$ deviations, respectively. The reasons why the simulations are not satisfactory for a given metabolite concentration in models 1-5 are shown qualitatively. There is no significant difference between models $6 a$ and $6 \mathrm{~b}$, and both of them are suitable for the simulation of the measured metabolite concentrations. For details, see Experimental procedures and (Doc. S4).

\begin{tabular}{|c|c|c|c|}
\hline \multirow{2}{*}{$\begin{array}{l}\text { Varied parameters in HD model as } \\
\text { compared to the 'basic' model }\end{array}$} & \multicolumn{3}{|c|}{ Effects of varied parameters on the goodness of simulation } \\
\hline & $\mathrm{DHAP}+\mathrm{GAP}$ & Pyruvate & Lactate \\
\hline 1. All measured $V_{\max }$ increased by $30 \%$ & Good & Too high & Little low \\
\hline 2. $V_{\max }(H K)$ increased by $30 \%$ & Good & Too high & Too low \\
\hline 3. $V_{\max }(\mathrm{GAPDH})$ two-fold increase & Little low & Good & Too low \\
\hline 4. 2 and 3 & Good & Too high & Little low \\
\hline $5 a K_{m}{ }^{\mathrm{GAP}}$ (GAPDH) from 20 to $5 \mu \mathrm{M}$ & Too low & Too low & Too low \\
\hline $\begin{array}{l}\text { 5b } K_{\mathrm{m}}^{\mathrm{GAP}} \text { (GAPDH) from } 20 \text { to } 5 \mu \mathrm{M} \\
K_{\mathrm{m}}{ }^{\mathrm{GAP}} \text { (aldolase) from } 300 \text { to } 75 \mu \mathrm{M}\end{array}$ & Too low & Too low & Too low \\
\hline $6 a 2$ and $5 a$ & Good & Very good & Very good \\
\hline $6 b 2$ and $5 b$ & Good & Very good & Very good \\
\hline
\end{tabular}


realistic steady-state concentration of pyruvate $(80 \mu \mathrm{M})$ in the cytosol. Figure $3 \mathrm{~A}$ shows the predicted time courses of the glycolytic pathway reaching the steadystate under in vivo conditions for the control and HD brain tissues. Because of the enhanced protein concentrations, there is a much reduced lag phase compared to that shown in Fig. 2. The steady-state flux is again predicted to be enhanced by a factor of 1.8 in the case of the HD brain compared to that of the normal control.

Next, we analysed the consequences of the increased intracellular ATP level measured in the HD sample (Table 4). The simulation predicted that the two-fold increase in the ATP concentration did not alter the steady-state flux of glycolysis (data not shown). We found that further variation of the concentrations of ADP (0.2-2 mM), NADH (0.1-1 mM) and NAD ${ }^{+}$ (1-2 mM) lead to an indistinguishable alteration in the glycolytic flux (data not shown).

The model used for prediction of the glycolytic fluxes also rendered it possible to estimate the steadystate metabolite levels. Figure 3B shows the changes of metabolite concentrations in the HD brain relative to the normal one. Comparison of the metabolite patterns calculated for the normal and HD brains revealed that: (a) the doubling of the ATP concentration should result in an enormous increase of all metabolite levels related to GAPDH and aldolase and (b) the absence of the reduction of $K_{\mathrm{m}}$ of GAP for GAPDH and aldolase should cause an elevation of all metabolite levels related to these enzymes. Therefore, the apparently modest alterations in the activities of the glycolytic enzymes should be expected to affect the pattern of glycolytic intermediates. This might lead to significant alterations of related pathways.

\section{Discussion}

$\mathrm{HD}$, one of the most extensively studied neurological disorders, is representative of a number of inherited diseases. The initiation of the disease process depends on the size of polyglutamine tails [32]. The cognitive and psychiatric decline is caused by the demise of neurones, most frequently in the caudate nucleus of the striatum within the basal ganglia of the brain. Nevertheless, we found the granular layer of the cerebellum to be enriched in nuclear inclusions without evidence of neuronal loss, indicating that there is no complete correlation between the presence of inclusions and neuronal damage. Recently, Arrasate et al. [33] demonstrated that inclusion body formation could act as a coping response to the presence of mutant huntingtin because it prolonged neuronal survival by
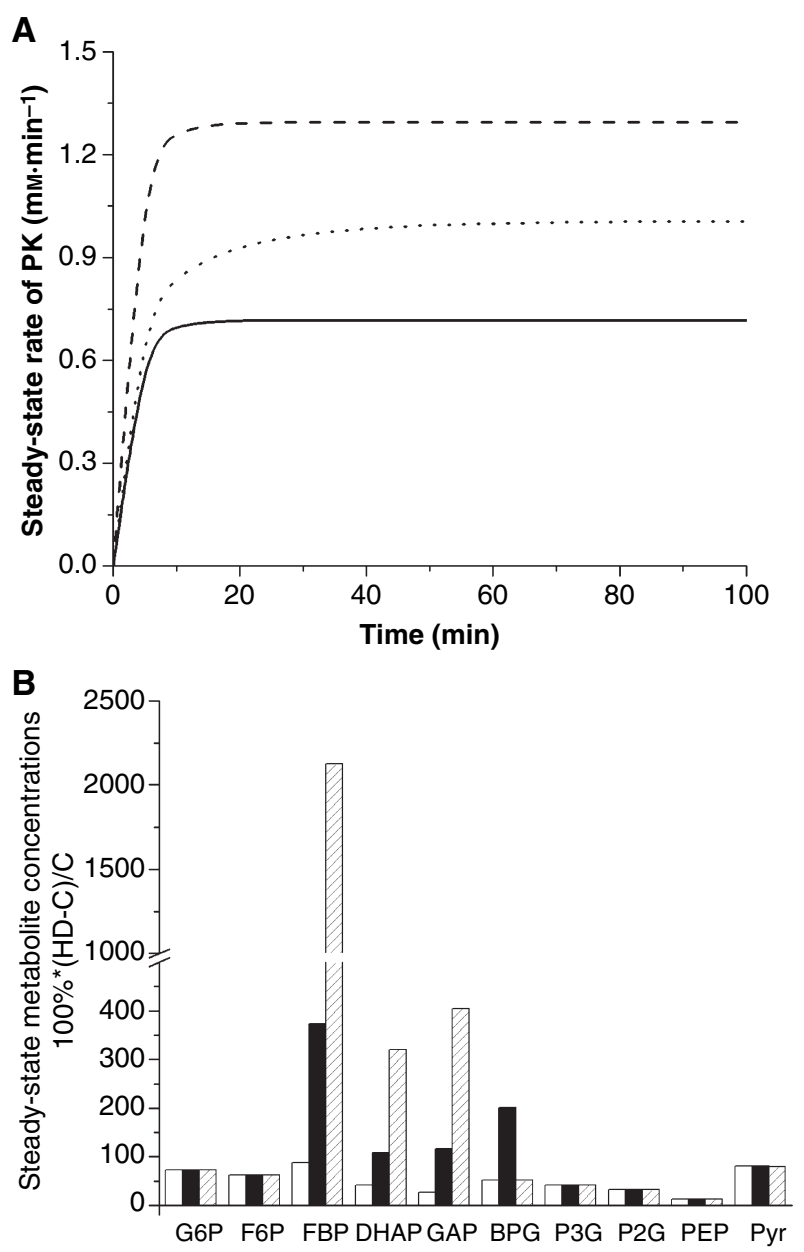

Fig. 3. Simulation of the glycolysis. (A) The steady-state flux of glucose conversion to lactate was simulated with the 'optimal' parameter set and rate equations shown in Table 2, Table 5 (model $6 \mathrm{~b}$ for the HD brain) and the Supporting information (Doc. S4) for the control (solid line) and the transgenic N171-82Q mice (dashed line). Simulation for the transgenic mice (dotted line) was also performed with a parameter set containing only the alterations detected in the activities of HK, GAPDH, enolase and PK. The concentrations of ATP (2 mM), ADP (0.2 mM), NAD (1 mM) and $\mathrm{NADH}(0.1 \mathrm{~mm})$ were kept constant. (B) The steady-state concentrations of the metabolites in the HD sample relative to those of the control were computed for the transgenic mice at reduced $K_{\mathrm{m}}$ (GAP) for GAPDH and aldolase, and increased $V_{\max }$ for $\mathrm{HK}$ (Table 5, model 6b) at $2 \mathrm{~mm}$ ATP concentration (white columns) and at $4 \mathrm{~mm}$ ATP concentration (black columns). The simulation was also carried out for the transgenic mice when no reduction in the $K_{\mathrm{m}}$ (GAP) for GAPDH and aldolase was included at $2 \mathrm{~mm}$ ATP concentration (striped columns). The steady-state metabolite levels in the case of control mice were 5.45, 0.85, 241, 23.8, 1.93, 20.8, $18.4,2.58,6.79$ and $89.6 \mu \mathrm{M}$ for glucose-6-phosphate (G6P), fructose-6-phosphate (F6P), fructose 1,6-bisphosphate (FBP), DHAP, GAP, 1,3-bisphosphoglycerate (BPG), 3-phosphoglycerate (P3G), 2-phosphoglycerate (P2G), phosphoenolpyruvate (PEP) and pyruvate, respectively. 
reducing the intracellular level of the toxic, diffuse form of mutant protein. The expression of the mutant huntingtin protein generally leads to mitochondrial dysfunction via direct or indirect effects. Decreased mitochondrial ATP production is considered to be a dominant characteristic of mitochondrial dysfunction [34]. Studies on STH $d h^{\mathrm{Q} 111}$ striatal cells suggested that the polyglutamine track implicated a dominant role of huntingtin in mitochondrial energy metabolism by regulating the mitochondrial ADP-phosphorylation in a $\mathrm{Ca}^{2+}$-dependent process [35]. The significantly increased activity of the CK system was considered as a compensatory mechanism for the decreased ATP level [36]. Dietary creatine supplementation delayed the behavioural and neuropathological phenotype and extended survival in N171-82Q mice [37], and creatine has also been shown to be protective in mitochondrial toxin models of HD [38]. In the striatum of HD patients, a decreased creatine level was found [11], which correlated with both clinical symptoms and CAG repeat number. These results parallel ours, namely, a modest increase in the activity of CK and a small decrease in the creatine level in the HD animal (Table 4). However, these small alterations could not result in significant increased ATP concentration that we found in brain tissue of HD transgenic mice compared to the control. The $\mathrm{CK}$ reaction is a side reaction to ATP synthesis only, and is unsuitable for long-time buffering of energetics.

In normal brain, the ATP level is controlled by ATP producing and ATP consuming processes. The main Gibbs energy (ATP) source in brain is glucose, which is metabolized by glycolysis in the cytosol to pyruvate, from which the terminal oxidation machinery in the mitochondrial compartment produces the major amount of ATP. Because we found much more significant alterations in the activities of the glycolytic enzymes (Table 2) than in the mitochondrial complexes (Table 3), we focused on an analysis of the kinetic parameters of the glycolytic enzymes, and on glycolytic flux, which should ultimately parallel both glycolytic and mitochondrial ATP production.

The enzyme GAPDH has been proposed to play a central role in causing the energy defect of HD brain [14]. Various scenarios have been suggested regarding the possible nature of the involvement of GAPDH and the CAG expansion of the mutant huntingtin protein. One such scenario is that the interaction between polyglutamine-containing proteins and GAPDH results in a reduced activity of this energy-metabolizing enzyme, leading to cell death in susceptible brain areas due to decreased energy stores [15]. In another scenario, the aberrant huntingtin-GAPDH interaction leads to overexpression of the enzyme and to cell death by apoptosis [15].

In the present study, we compared the activity of GAPDH in the posterior region, including hippocampus, striatum and thalamus (Table 1 and Fig. 1) of HD transgenic and 3-NP-treated mice, with that of the corresponding region of control mice. The activity measurements carried out at substrate saturation $\left(V_{\max }\right.$ conditions) showed that the GAPDH activity decreased by approximately $50 \%$ in both mouse models (Table 2). No difference was detected when the unaffected regions of the HD and control animals were compared (data not shown).

The decreased activity of the GAPDH due to the expression of mutant huntingtin protein that we observed is supported by the results obtained from fibroblast experiments (J. Oláh, J. Raskó, F. Uler, J. Ovádi, unpublished results). The fibroblast cells were established from $\mathrm{HD}$ patients with different CAG repeat extensions. We found that the GAPDH activity was reduced by $20-55 \%$ with respect to the control, without clear correlation between the extension of CAG repeats and decrease of GAPDH activity. This result is consistent with that reported from other laboratories $[16,17]$. Thus, we suggest that the presence of the mutant huntingtin protein in HD transgenic mice, and the neurotoxin treatment in wild-type mice causes the substantial loss of GAPDH activity.

These findings apparently contradict those obtained with postmortem brain tissues $[8,15]$. In morphologically affected and unaffected regions of the post mortem brain in the case of CAG repeat disorders, the activity of GAPDH bound to the mutant proteins [15] was normal or near normal. One way to interpret these data is that the inhibition of GAPDH by its interaction with the mutant huntingtin protein does not persist in post mortem brain tissue due to the reversibility of the inhibition.

Despite the fact that the activity of GAPDH was found to be decreased in both mouse models, we measured a higher glycolytic flux in the case of the HD sample compared to the control (Fig. 2). This finding was verified by measuring the glycolytic flux in different brain regions of HD mice (posterior, anterior and cerebellum). The most affected (posterior) region exhibited the fastest glycolytic flux, and other regions showed modest but still higher flux compared to that of the corresponding regions of the control (data not shown). This finding is consistent with the results of a recent study where glucose metabolism varied depending on the region used for measurements [13]. Using positron emission tomography, decreased striatal glucose metabolism, thalamic and cerebellar 
hypermetabolism were detected in the case of HD patients. Thus, we propose that the characteristic enhancement of the initial conversion rate of glucose coupled with $\mathrm{NAD}^{+} / \mathrm{NADH}$ conversion could be a marker for early diagnosis of HD. Indeed, increased metabolism was recently explored in the R6/2 mouse model of $\mathrm{HD}$ as detected by the increased oxygen consumption, which was coupled with weight loss [39]. We also noticed weight loss in HD mice during the development of the disease.

Our results appeared to be internally inconsistent when focusing on GAPDH alone: the level of this enzyme was decreased, leading to the observed increase in triosephosphates. However, a decrease in glycolytic flux and ATP levels might be expected if this were the sole initial change in HD. The mathematical modelling based upon the measured kinetic parameters of the individual enzymes determined experimentally (Table 2) and the rate equations of the enzyme reactions (Doc. S4) rendered it possible to examine this molecule-based expectation in terms of the possible network effects. Our calculations revealed that the altered activities of the glycolytic enzymes determined in the affected region of HD transgenic mice should enhance the rate of the glycolytic flux compared to the control, even though the GAPDH activity was decreased rather than increased in HD. The minor increased activity of hexokinase should be expected to have more effect on the flux because that enzyme has a higher flux control coefficient than GAPDH.

ATP levels were up rather than down in HD tissues. Taken together, the findings of reduced GAPDH activity, increased glycolytic flux and increased ATP suggest that the previous hypotheses $[14,15]$, in which reduced GAPDH function lead to decreased energy metabolism, reduced ATP levels and hence the further pathology of HD, may not apply to our experimental model system, and perhaps not to HD either.

To learn more from the experimental data, we engaged in inverse modelling, aiming to find changes in regulation that might explain the slight differences between the experimental and modelling results. The optimal parameter set that appropriately described the time-dependent concentration of the three metabolites, triosephosphates, pyruvate and lactate, contained the reduction of $K_{\mathrm{m}}$ values of GAP for GAPDH and aldolase. The reduction of these $K_{\mathrm{m}}$ values predicted by simulation could not be detected in the individual enzyme assays. This situation occurred at the system level when the intermediate could be directly transferred from the active site of the donor enzyme to that of the acceptor enzyme without its diffusion into the bulk solution [40]. The hypothesized channelling of
GAP derived by the heterologous enzyme association, aldolase/GAPDH, could be promoted by the sticking of GAPDH to the polyglutamine tail of the mutant huntingtin protein, as proposed previously [14]. We have no direct evidence for the direct interaction of GAPDH and mutant huntingtin, nor for the microcompartmentation of GAP in pathological brain; however, the in vitro binding data [14] and our experimental-based modelling may provide a plausible explanation for the mechanism manifests itself only in the HD brain tissue.

The mathematical modelling made it possible to predict the metabolic state and the steady-state flux of glucose metabolism at more physiological conditions (i.e. at higher protein concentrations) than used in the test tube experiments. The biosimulation referring to steady-state conditions at high protein concentrations suggested that HD could result in a significant shift in the metabolic state of the brain tissue in the case of the transgenic mice (Fig. 3), which could then affect other cellular processes. For example, the elevation of hexosephosphate concentrations may influence the penthosephosphate pathway by increasing the rate of the reaction catalysed by glucose-6-phosphate dehydrogenase (EC 1.1.1.49). Jenkins et al. [41,42] investigated the impact of CAG repeat length, huntingtin protein length and protein context on cerebral metabolism in HD. They found significant alterations in $N$-acetylaspartate, glutamine, glutamate and glucose levels and suggested that the development of the disease could be related to a fundamental perturbation of the metabolic status. The different energy state found for the HDaffected brain could influence many ATP-related metabolic, signalling, membrane and proteolytic processes.

The data obtained in the present study did not reveal decreased mitochondrial complex activities in the N171-82Q mouse model. This observation is in accordance with those of Guidetti et al. [43], who obtained similar data with full-length mutant huntingtin cDNA transgenic mice. Examination of the neostriatum and cerebral cortex in human presymptomatic and pathological grade $1 \mathrm{HD}$ cases also showed no change in the activity of mitochondrial complexes I-IV; reduced activities of mitochondrial complexes were found only in late-stage HD brains [43]. These data may indicate that the mitochondrial dysfunction established in HD mice is not necessarily concomitant with the reduced activity of mitochondrial complexes. It could be suggested that the mitochondrial energy impairment is a consequence, rather than a cause, of early neuropathological changes. It should be noted that, in the 3-NP-treated mouse model, and in accordance with other reports [44], the activity of 
mitochondrial complex II was depressed. This was accompanied by alterations in the activities of some glycolytic enzymes that were not identical to those obtained with transgenic mouse (Table 2), despite the fact that the 3-NP induced striatal pathology resembled the observed pathology in HD patients [21].

Finally, one more issue that needs to be discussed is the relation of the damaged neurones and the enhanced ATP concentration at the tissue level demonstrated in the present study. The higher ATP concentration might be explained by faster glycolytic flux in HD brain relative to the control. This does not mean, however, that this situation exists in the vulnerable striatal neurones in HD. Our studies were performed with brain tissues containing different types of neuronal cells as well as a large excess of glial cells. Astrocytes, a sub-type of the glial cells (outnumbering the neurones by ten to one), play a critical role as an important Gibbs energy source, with interactions between neurones and astrocytes being critical for brain energy metabolism [45]. Despite the fact that glucose is the primary energy source for both neurones and astrocytes [46], neurones can utilize glial-produced lactate as an additional energy substrate in special situations [47]. The appearance of the 'sick' neuronal cells may switch on signaling process(es) resulting in enhanced intracellular (glial) ATP levels. Therefore, a plausible explanation for our finding of an increased ATP level in HD brain, as previously shown in a striatal cell line [35], is that the reduced neuronal ATP level could be compensated/overcompensated by the activity/activation of the ATP producing machinery of the astrocytes at the tissue level. In a recent review, activation of microglia was reported in HD patients, which could result in a self-propagating inflammatory cascade leading to apoptosis, or might play a protective role by promoting neurogenesis [48]. Microglial activation often precedes any reaction of other cell types in the brain. NO-mediated inhibition of cellular respiration was followed by mitochondrial depolarization and cell death in neurones, but hyperpolarization in astrocytes, and an increase in the energy state at the expense of glycolytically generated ATP, prevented apoptotic death in astrocytes [49].

\section{Experimental procedures}

\section{Animals}

All animal experiments were carried out in accordance with the European Union Guide for the Care and Use of Laboratory Animals and were approved by the local animal care committee. For ethical reasons, the number of experiments was restricted (see below). 3-NP (Sigma, St Louis, MO, USA) was dissolved in $\mathrm{NaCl} / \mathrm{P}_{\mathrm{i}}(10 \mathrm{~mm}$ phosphate buffer, $\mathrm{pH} 7.4$, containing $120 \mathrm{mM} \mathrm{NaCl}$ ) and injected intraperitoneally at a dose of $50 \mathrm{mg} \cdot \mathrm{kg}^{-1}$ into CFLP mice (twice a day). Mice from the same strain received $\mathrm{NaCl} / \mathrm{P}_{\mathrm{i}}$ vehicle and were used as a control. Mice were sacrificed after the seventh 3-NP injection. Transgenic mice expressing a cDNA encoding an N-terminal fragment (171 amino acids) of human huntingtin with 82 glutamine residues were used in these studies [24]. Transgenic breeder pairs, purchased from Jackson Laboratories (Bar Harbor, ME, USA), were bred locally. Male transgenic mice from the N171-82Q line were then bred with female $\mathrm{B} 6 \mathrm{C} 3 \mathrm{~F} 1$ mice (background strain). As controls, wild-type littermates were used. The offsprings were genotyped with a PCR assay on tail DNA [24]. The mice were housed under standard conditions with free access to water and food. Mice were sacrificed at the age of 20 weeks. The brains were rapidly removed and cut into two hemispheric pieces. Both halves of the brains were cut at the level of the chiasma opticum. Three portions were separated: (a) the frontal cortex and anterior part of the striatum; (b) the posterior part of the striatum, hippocampus, thalamus, parietal and occipital cortices; and (c) the cerebellum with brainstem; referred to as anterior, posterior and cerebellum, respectively. The brain pieces were kept at $-70{ }^{\circ} \mathrm{C}$. For the dissection, mouse brain matrices were used for slicing the exact intervals. In the case of mice treated with 3-NP, the same separation process was applied to compare the two mouse models of the disease.

\section{Antibody, cytochrome $\mathrm{c}^{2+}$ and $\mathrm{c}^{3+}$ solutions}

The huntingtin antibody directed against the first 17 amino acids of the N-terminal part of the huntigtin was kindly provided by L. Jones (University of Wales, College of Medicine, Cardiff, UK). It recognizes both mutant and normal huntingtin. Cytochrome $\mathrm{c}^{3+}$ was dissolved in phosphate buffer (10 mM potassium phosphate, $\mathrm{pH}$ 7.0). The solution (approximately $1 \mathrm{mg} \cdot \mathrm{mL}^{-1}$ ) was reduced with a few mgs of potassium ascorbate. Excess ascorbate was removed by dialysis against the above phosphate buffer for $18-24 \mathrm{~h}$ at $4{ }^{\circ} \mathrm{C}$. The reduced cytochrome $\mathrm{c}^{2+}$ was stored at $-20^{\circ} \mathrm{C}$.

\section{Preparation of extracts}

\section{Cytosolic extract}

Cell free extracts were prepared from brain tissues by homogenization at $4{ }^{\circ} \mathrm{C}$ using a Potter-homogenizer in buffer A $[50 \mathrm{~mm}$ Tris, $\mathrm{pH} 7.4$, containing $120 \mathrm{~mm} \mathrm{NaCl}$, $10 \mu \mathrm{M} 4$-(2-aminoethyl) benzenesulfonyl fluoride hydrochloride, $1 \mu \mathrm{g} \cdot \mathrm{mL}^{-1}$ of pepstatin, $1 \mu \mathrm{g} \cdot \mathrm{mL}^{-1}$ of leupeptin] at a $1: 1.5$ ratio $(\mathrm{w} / \mathrm{w})$ of tissue and buffer, then centrifuged at $15000 \mathrm{~g}$ for $20 \mathrm{~min}$ at $4{ }^{\circ} \mathrm{C}$. The supernatant was used as cytosolic fraction for glycolytic enzyme assays. The activity 
of the cytosolic marker LDH was determined in the supernatant.

\section{Crude mitochondrial extract}

Brain tissues were homogenized in buffer B [20 mM potassium phosphate, $\mathrm{pH} 7.6$, containing $150 \mathrm{~mm} \mathrm{KCl}, 1 \mathrm{~mm}$ EDTA, $10 \mu \mathrm{M}$ 4-(2-aminoethyl) benzenesulfonyl fluoride hydrochloride, $1 \mu \mathrm{g} \cdot \mathrm{mL}^{-1}$ of pepstatin, $1 \mu \mathrm{g} \cdot \mathrm{mL}^{-1}$ of leupeptin] at a 1:4 ratio of tissue and buffer, and centrifuged at $1000 \mathrm{~g}$ for $5 \mathrm{~min}$ at $4{ }^{\circ} \mathrm{C}$. The supernatant was further centrifuged at $14000 \mathrm{~g}$ for $25 \mathrm{~min}$ at $4{ }^{\circ} \mathrm{C}$. The pellet of the second centrifugation was enriched in mitochondria used for assays of the activity of mitochondrial complexes. The 'intactness' of the mitochondria was tested by measuring the activity of GLUDH as mitochondrial marker.

\section{Protein determination}

Routine measurements of protein concentration were performed using the Bradford method [50].

\section{Enzyme kinetic measurements}

\section{Cytosolic enzyme assays}

Measurements of enzyme activities were based on the production of NADPH/NADH, or consumption of NADH, using auxiliary enzyme systems, if necessary. The experiments were carried out in buffer $\mathrm{C}(100 \mathrm{~mm}$ Tris, $\mathrm{pH} 8.0$, containing $10 \mathrm{mM}$ phosphate and $10 \mathrm{mM} \mathrm{MgCl}_{2}$ ) at $25^{\circ} \mathrm{C}$ using a Cary 100 spectrophotometer (Varian Inc., Palo Alto, CA, USA) at $340 \mathrm{~nm}$. Glycolytic enzyme activities were determined as previously described [51]. The GAPDH assay was carried out in standard buffer containing $5 \mathrm{~mm}$ arsenate, $4 \mathrm{mM} \mathrm{NAD}^{+}$and $2 \mathrm{~mm}$ GAP as substrate. CK activity assay was performed at $340 \mathrm{~nm}$ in buffer D (100 mM Tris, pH 7.0, containing $10 \mathrm{~mm}$ phosphate and $10 \mathrm{mM} \mathrm{MgCl}_{2}$ ). The reaction mixture contained $1 \mathrm{~mm}$ creatine phosphate, $1 \mathrm{~mm} \mathrm{NADP}{ }^{+}, 1 \mathrm{~mm}$ glucose, plus glucose6-phosphate dehydrogenase and HK as auxiliary enzymes. The reaction was initiated by adding $2 \mathrm{~mm}$ MgADP.

\section{Mitochondrial respiratory chain complex activity assays}

The experiments were carried out in buffer E $(50 \mathrm{~mm}$ potassium phosphate, $\mathrm{pH} 7.5$ ) at $37{ }^{\circ} \mathrm{C}$ by a Cary 100 spectrophotometer as described previously [52] with some modifications (Doc. S1).

\section{Flux measurements}

The conversion of glucose via the glycolytic pathway was measured in cytosolic extract (see above) at $25{ }^{\circ} \mathrm{C}$ in buf- fer C containing $4 \mathrm{~mm} \mathrm{NAD}{ }^{+}, 2 \mathrm{~mm}$ glucose and $2 \mathrm{~mm}$ MgATP. The extract was preincubated with $\mathrm{NAD}^{+}$and MgATP for $5 \mathrm{~min}$, and then the reaction was started by adding glucose to the reaction mixture. The reaction was followed spectrophotometrically at $340 \mathrm{~nm}$ by monitoring NADH production, and by determining the concentrations of the triosephosphates, pyruvate and lactate. The reaction was stopped at various times by addition of ice cold $\mathrm{HClO}_{4}$. After neutralization of the samples, the concentrations of the metabolites were determined by enzymatic assays (for details see Doc. S2).

\section{Determination of ATP and creatine levels}

$\mathrm{HClO}_{4}$ was added to the cell free extract of brain prepared from different brain areas of transgenic mice or mice treated with 3-NP. After neutralization, the ATP level was determined in buffer $\mathrm{C}$ in the presence of $1 \mathrm{~mm}$ glucose, $1 \mathrm{mM} \mathrm{NADP}^{+}$, HK and glucose 6-phosphate-dehydrogenase as auxiliary enzymes. The creatine level was measured in $200 \mathrm{~mm}$ glycine buffer at $\mathrm{pH} 9.6$, containing $2 \mathrm{~mm}$ MgATP, $0.25 \mathrm{~mm}$ NADH and $2 \mathrm{~mm}$ phosphoenolpyruvate, with $\mathrm{CK}, \mathrm{PK}$ and $\mathrm{LDH}$ as auxiliary enzymes.

\section{Simulation tools}

All the numerical simulations were performed with the MATHEMATICA FOR STUDENTS software package, version 4.2 (Wolfram Research; http://www.wolfram.com). The wellestablished rate equations of the glycolytic enzymes used for computation of the glycolytic pathway are presented in the Supporting information (Doc. S4). These have been submitted to the model bases JWS/Silicon cell (http:// www.jjj.bio.vu.nl) and BioModels. For the simulation of the extract experiments (Fig. 2), the experimentally observed $V_{\max }$ were used. For the simulation of the glycolytic pathway at near-physiological circumstances (Fig. 3), protein concentrations 100 -fold higher than used in the test tube experiments were introduced into the model and constant concentrations of glucose, $\mathrm{NAD}^{+}, \mathrm{NADH}, \mathrm{ATP}$ and ADP were applied. The high $\left(30 \mathrm{mg} \cdot \mathrm{mL}^{-1}\right)$ protein concentration was estimated on the grounds that the concentrations of the prepared cytosolic extracts were $10-15 \mathrm{mg} \cdot \mathrm{mL}^{-1}$ after an at least two- to three-fold dilution.

\section{Immunohistochemistry}

4\% Paraformaldehyde fixed, paraffin-embedded material from the half-brain (see above) of five of each transgenic and control mice were used for neuropathological evaluation. The other half of the brain was deep frozen. In addition to hematoxylin and eosin and luxol-cresyl violet routine stainings, for immunohistochemistry, anti-ubiquitin (1:200, rabbit-polyclonal; Dako, Glostrup, Denmark), 
anti-huntingtin (1:100, rabbit-polyclonal; courtesy of Lesley Jones, University of Wales College of Medicine, Cardiff, UK) and anti-GFAP (rabbit-polyclonal; Dako, Glostrup, Denmark) sera were applied. As a secondary system, we used the Envision detection kit (Dako).

\section{Acknowledgements}

We are grateful to Lesley Jones (University of Wales College of Medicine, Cardiff, UK) for providing the anti-huntingtin serum. This work was supported by Hungarian National Scientific Research Fund Grants OTKA T-046071 and T-067963 to J. Ovádi, T-049247 to F.O., and PD 76793 to J. Ovádi; FP6-2003-LIFESCIHEALTH-I: BioSim and NKFP-MediChem2 1/A/ 005/2004 to J. Oláh; and by RET-NORT 08/2004 and ETT 215/2006 to P.K. and L.V.; as well as by various grants from EPSRC, BBSRC, NGI, NWO and the FP7 program to H.V.W.

\section{References}

1 Purdon SE, Mohr E, Ilivitsky V \& Jones BD (1994) Huntington's disease: pathogenesis, diagnosis and treatment. J Psychiatry Neurosci 19, 359-367.

2 Walker FO (2007) Huntington's disease. Lancet 369, 218-228.

3 DiFiglia M, Sapp E, Chase KO, Davies SW, Bates GP, Vonsattel JP \& Aronin N (1997) Aggregation of huntingtin in neuronal intranuclear inclusions and dystrophic neurites in brain. Science 277, 1990-1993.

4 The Huntington's Disease Collaborative Research Group (1993) A novel gene containing a trinucleotide repeat that is expanded and unstable on Huntington's disease chromosomes. Cell 72, 971-983.

5 Perez-De La Cruz V \& Santamaria A (2006) Integrative hypothesis for Huntington's disease: a brief review on experimental evidence. Physiol Res 56, 513-526.

6 Landles C \& Bates GP (2004) Huntingtin and the molecular pathogenesis of Huntington's disease. Fourth in molecular medicine review series. EMBO Rep 5, 958-963.

7 Beal MF (2000) Energetics in the pathogenesis of neurodegenerative diseases. Trends Neurosci 23, 298-304.

8 Browne SE, Bowling AC, MacGarvey U, Baik MJ, Berger SC, Muqit MM, Bird ED \& Beal MF (1997) Oxidative damage and metabolic dysfunction in Huntington's disease: selective vulnerability of the basal ganglia. Ann Neurol 41, 646-653.

9 Gu M, Gash MT, Mann VM, Javoy-Agid F, Cooper JM \& Schapira AH (1996) Mitochondrial defect in Huntington's disease caudate nucleus. Ann Neurol 39, 385-389.

10 Jenkins BG, Koroshetz WJ, Beal MF \& Rosen BR (1993) Evidence for impairment of energy metabolism in vivo in Huntington's disease using localized $1 \mathrm{H}$ NMR spectroscopy. Neurology 43, 2689-2695.

11 Sanchez-Pernaute R, Garcia-Segura JM, del Barrio Alba A, Viano J \& de Yebenes JG (1999) Clinical correlation of striatal 1H MRS changes in Huntington's disease. Neurology 53, 806-812.

12 Hoang TQ, Bluml S, Dubowitz DJ, Moats R, Kopyov O, Jacques D \& Ross BD (1998) Quantitative protondecoupled 31P MRS and 1H MRS in the evaluation of Huntington's and Parkinson's diseases. Neurology 50, 1033-1040.

13 Ma Y \& Eidelberg D (2007) Functional imaging of cerebral blood flow and glucose metabolism in Parkinson's disease and Huntington's disease. Mol Imaging Biol 9, 223-233.

14 Burke JR, Enghild JJ, Martin ME, Jou Y-S, Myers RM, Roses AD, Vance JM \& Strittmatter WJ (1996) Huntingtin and DRPLA proteins selectively interact with the enzyme GAPDH. Nat Med 2, 347-350.

15 Kish SJ, Lopes-Cendes I, Guttman M, Furukawa Y, Pandolfo M, Rouleau GA, Ross BM, Nance M, Schut L, Ang L et al. (1998) Brain glyceraldehyde-3-phosphate dehydrogenase activity in human trinucleotide repeat disorders. Arch Neurol 55, 1299-1304.

16 Cooper AJ, Sheu KF, Burke JR, Strittmatter WJ \& Blass JP (1998) Glyceraldehyde-3-phosphate dehydrogenase abnormality in metabolically stressed Huntington disease fibroblasts. Dev Neurosci 20, 462-468.

17 Mazzola JL \& Sirover MA (2001) Reduction of glyceraldehyde-3-phosphate dehydrogenase activity in Alzheimer's disease and in Huntington's disease fibroblasts. $J$ Neurochem 76, 442-449.

18 Senatorov VV, Charles V, Reddy PH, Tagle DA \& Chuang DM (2003) Overexpression and nuclear accumulation of glyceraldehyde-3-phosphate dehydrogenase in a transgenic mouse model of Huntington's disease. Mol Cell Neurosci 22, 285-297.

19 Bae BI, Hara MR, Cascio MB, Wellington CL, Hayden MR, Ross CA, Ha HC, Li XJ, Snyder SH \& Sawa A (2006) Mutant huntingtin: nuclear translocation and cytotoxicity mediated by GAPDH. Proc Natl Acad Sci USA 103, 3405-3409.

20 Menalled LB \& Chesselet MF (2002) Mouse models of Huntington's disease. Trends Pharmacol Sci 23, 32-39.

21 Klivenyi P, Starkov AA, Calingasan NY, Gardian G, Browne SE, Yang L, Bubber P, Gibson GE, Patel MS \& Beal MF (2004) Mice deficient in dihydrolipoamide dehydrogenase show increased vulnerability to MPTP, malonate and 3-nitropropionic acid neurotoxicity. $J$ Neurochem 88, 1352-1360.

22 Brouillet E, Conde F, Beal MF \& Hantraye P (1999) Replicating Huntington's disease phenotype in experimental animals. Prog Neurobiol 59, 427-468. 
23 Mangiarini L, Sathasivam K, Seller M, Cozens B, Harper A, Hetherington C, Lawton M, Trottier Y, Lehrach H, Davies SW et al. (1996) Exon 1 of the HD gene with an expanded CAG repeat is sufficient to cause a progressive neurological phenotypes in transgenic mice. Cell 87, 493-506.

24 Schilling G, Becher MW, Sharp AH, Jinnah HA, Duan K, Kotzuk JA, Slunt HH, Ratovitski T, Cooper JK, Jenkins NA et al. (1999) Intranuclear inclusions and neuritic aggregates in transgenic mice expressing a mutant N-terminal fragment of huntingtin. Hum Mol Genet 8, 397-407.

25 Klivenyi P, Bende Z, Hartai Z, Penke Z, Nemeth H, Toldi J \& Vecsei L (2006) Behaviour changes in a transgenic model of Huntington's disease. Behav Brain Res 169, 137-141.

26 Hedreen JC \& Folstein SE (1995) Early loss of neostriatal striosome neurons in Huntington's disease. J Neuropathol Exp Neurol 54, 105-120.

27 Teusink B, Passarge J, Reijenga CA, Esgalhado E, van der Weijden CC, Schepper M, Walsh MC, Bakker BM, van Dam K, Westerhoff HV et al. (2000) Can yeast glycolysis be understood in terms of in vitro kinetics of the constituent enzymes? Testing biochemistry. Eur $J$ Biochem 267, 5313-5329.

28 Snoep JL, Bruggeman F, Olivier BG \& Westerhoff HV (2006) Towards building the silicon cell: a modular approach. Biosystems 83, 207-216.

29 Westerhoff HV, Kolodkin A, Conradie R, Wilkinson SJ, Bruggeman FJ, Krab K, van Schuppen JH, Hardin H, Bakker BM, Moné MJ et al. (2008) Systems biology towards life in silico: mathematics of the control of living cells. J Math Biol [Epub ahead of print].

$30 \mathrm{Wu}$ J, Takeo T, Wakui M, Ellsworth K \& Fisher RS (2003) Intracellular energy failure does not underlie hyperthermic spreading depressions in immature rat hippocampal slice. Brain Res 987, 240-243.

31 Aubert A \& Costalat R (2002) A model of the coupling between brain electrical activity, metabolism, and hemodynamics: application to the interpretation of functional neuroimaging. Neuroimage 17, 1162-1181.

32 Gusella JF \& MacDonald ME (2000) Molecular genetics: unmasking polyglutamine triggers in neurodegenerative disease. Nat Rev Neurosci 1, 109-115.

33 Arrasate M, Mitra S, Schweitzer ES, Segal MR \& Finkbeiner S (2004) Inclusion body formation reduces levels of mutant huntingtin and the risk of neuronal death. Nature 431, 805-810.

34 Marcinek DJ (2004) Mitochondrial dysfunction measured in vivo. Acta Physiol Scand 182, 343-352.

35 Seong IS, Ivanova E, Lee JM, Choo YS, Fossale E, Anderson M, Gusella JF, Laramie JM, Myers RH, Lesort M et al. (2005) HD CAG repeat implicates a dominant property of huntingtin in mitochondrial energy metabolism. Hum Mol Genet 14, 2871-2880.
36 Kasparová S, Sumbalová Z, Bystrický P, Kucharská J, Liptaj T, Mlynárik V \& Gvozdjáková A (2006) Effect of coenzyme Q10 and vitamin E on brain energy metabolism in the animal model of Huntington's disease. Neurochem Int 48, 93-99.

37 Andreassen OA, Dedeoglu A, Ferrante RJ, Jenkins BG, Ferrante KL, Thomas M, Friedlich A, Browne SE, Schilling G, Borchelt DR et al. (2001) Creatine increase survival and delays motor symptoms in a transgenic animal model of Huntington's disease. Neurobiol Dis $\mathbf{8}$, 479-491.

38 Matthews RT, Yang L, Jenkins BG, Ferrante RJ, Rosen BR, Kaddurah-Daouk R \& Beal MF (1998) Neuroprotective effects of creatine and cyclocreatine in animal models of Huntington's disease. J Neurosci 18, 156-163.

39 van der Burg JM, Bacos K, Wood NI, Lindqvist A, Wierup N, Woodman B, Wamsteeker JI, Smith R, Deierborg T, Kuhar MJ et al. (2008) Increased metabolism in the R6/2 mouse model of Huntington's disease. Neurobiol Dis 29, 41-51.

40 Ovádi J (1995) Cell Architecture and Metabolic Channeling. Springer-Verlag, New York, NY.

41 Jenkins BG, Andreassen OA, Dedeoglu A, Leavitt B, Hayden M, Borchelt D, Ross CA, Ferrante RJ \& Beal MF (2005) Effects of CAG repeat length, HTT protein length and protein context on cerebral metabolism measured using magnetic resonance spectroscopy in transgenic mouse models of Huntington's disease. $J$ Neurochem 95, 553-562.

42 Jenkins BG, Klivenyi P, Kustermann E, Andreassen OA, Ferrante RJ, Rosen BR \& Beal MF (2000) Nonlinear decrease over time in $\mathrm{N}$-acetyl aspartate levels in the absence of neuronal loss and increases in glutamine and glucose in transgenic Huntington's disease mice. J Neurochem 74, 2108-2119.

43 Guidetti P, Charles V, Chen EY, Reddy PH, Kordower JH, Whetsell WOJ, Schwarcz R \& Tagle DA (2001) Early degenerative changes in transgenic mice expressing mutant huntingtin involve dendritic abnormalities but no impairment of mitochondrial energy production. Exp Neurol 169, 340-350.

44 Saulle E, Gubellini P, Picconi B, Centonze D, Tropepi D, Pisani A, Morari M, Marti M, Rossi L, Papa M et al. (2004) Neuronal vulnerability following inhibition of mitochondrial complex II: a possible ionic mechanism for Huntington's disease. Mol Cell Neurosci 25, 9-20.

45 Ovádi J \& Orosz F (2007) Energy metabolism in conformational diseases. In Biosimulation in Drug Development (Bertau M, Mosekilde E \& Westerhoff $\mathrm{H}$, eds), pp. 233-257. Wiley, Weinheim.

46 Chih CP, Lipton P \& Roberts ELJ (2001) Do active cerebral neurons really use lactate rather than glucose? Trends Neurosci 24, 573-578. 
47 Pellerin L \& Magistretti PJ (1994) Glutamate uptake into astrocytes stimulates aerobic glycolysis: a mechanism coupling neuronal activity to glucose utilization. Proc Natl Acad Sci USA 91, 10625-10629.

48 Tai YF, Pavese N, Gerhard A, Tabrizi SJ, Barker RA, Brooks DJ \& Piccini P (2007) Imaging microglial activation in Huntington's disease. Brain Res Bull 72, 148-151.

49 Almeida A, Almeida J, Bolanos JP \& Moncada S (2001) Different responses of astrocytes and neurons to nitric oxide: the role of glycolytically generated ATP in astrocyte protection. Proc Natl Acad Sci USA 98, 15294-15299.

50 Bradford MM (1976) A rapid and sensitive method for the quantitation of microgram quantities of protein utilizing the principle of protein-dye binding. Anal Biochem 72, 248-254.

51 Beutler E, Blume KG, Kaplan JC, Löhr GW, Ramot B \& Valentine WN (1977) International Committee for Standardization in Haematology: recommended methods for red-cell enzyme analysis. $\mathrm{Br} J$ Haematol 35, 331-340.

52 Barrientos A, Kenyon L \& Moraes CT (1998) Human xenomitochondrial cybrids. Cellular models of mitochondrial complex I deficiency. J Biol Chem 273, 14210-14217.

\section{Supporting information}

The following supplementary material is available:

Doc. S1. Assays of the activities of the mitochondrial respiratory chain complexes.

Doc. S2. Determination of metabolite concentrations to follow fluxes.

Doc. S3. Western blot.

Doc. S4. Rate equations and kinetic parameters used for the simulation.

This supplementary material can be found in the online version of this article.

Please note: Wiley-Blackwell are not responsible for the content or functionality of any supplementary material supplied by the authors. Any queries (other than missing material) should be directed to the corresponding author for the article. 